\title{
Dermatoloji Polikliniğine Bașvuran Erișkin Obez Hastalarda Görülen Deri Bulgularının Değerlendirilmesi
}

\section{Evaluation of Skin Findings in Adult Obese Dermatology Outpatients}

\section{Hilal Kaya Erdoğan, Gonca Gökdemir, Sevim Purisa*, İlknur Kıvanç Altunay}

Șịsli Etfal Eğitim ve Araștırma Hastanesi, Deri ve Zührevi Hastalıklar Kliniği, İstanbul, Türkiye *İstanbul Üniversitesi İstanbul Tıp Fakültesi, Biyoistatistik ve Tıp Bilișimi Anabilim Dalı, İstanbul, Türkiye

\section{Özet}

Amaç: Literatürde obezlerde görülen deri bulgularını inceleyen çalıșmalar sınırlı olup ülkemizde bu konuda yapılmıș çalıșma yoktur. Hastanemiz dermatoloji polikliniğine bașvuran obez hastalarda görülen deri bulgularını saptamayı ve obez olmayan hastalar ile karșilaștırmayı amaçladık.

Gereç ve Yöntem: Dermatoloji polikliniğine bașvuran 300 obez ve 340 obez olmayan toplam 640 hasta çalıșmaya alındı. Tüm hastaların; sosyodemografik özellikleri, eșlik eden sistemik hastalık varlığı sorgulandı. Boy ve kiloları ölçülerek beden kitle indeksleri (BKI) hesaplandı. Dermatolojik muayeneleri yapılarak, klinik bulguları kaydedildi. Veriler istatistiksel olarak değerlendirildi.

Bulgular: Çalıșmaya alınan hastalar iki gruba ayrıldı. Çalıșma grubu 300 obez hastadan olușuyordu (229 kadın, 71 erkek, yaș ort: 45,89). Kontrol grubunda ise obez olmayan 340 hasta mevcuttu (160 kadın, 180 erkek, yaș ort: 38,99). Çalıșma grubundaki hastaların yaș ortalaması ve kadın hastalarınn sayısı, kontrol grubuna göre istatistiksel olarak anlamlı derecede daha fazlaydı $(p<0,0001)$. Çalıșma grubundaki saptanan en sık 5 hastalık sırasıyla; akrokordon (\%53,3), plantar hiperkeratoz $(\% 29,6)$, mantar infeksiyonları $(\% 25,3)$, stria $(\% 20,3)$ ve akantozis nigrikans $(\% 15,3)$ idi. Çalıșma grubundaki kadın hastalarda görülen mantar hastalıkları, variköz venler ve intertrigo, erkek hastalara göre istatistiksel olarak anlamlı derecede daha fazlaydı. Çalıșma grubundaki hastalar içinde, spesifik deri bulgusu olan ve olmayanların BKI'leri karșılaștırıldığında akrokordon, akantozis nigrikans ve plantar hiperkeratoz olanların BKI'leri, bu hastalıklara sahip olmayanlara göre istatistiksel olarak anlamlı derecede daha fazlaydı.

Sonuç: Calıșmamızda obez hastalarda en fazla görülen ilk bes hastalık akrokordon, plantar hiperkeratoz, mantar infeksiyonları, stria ve akantozis nigrikans olarak saptanmıștır. Obezlerde deride olușan patofizyolojik özelliklerin aydınlatılmasına yönelik çalıșmalar, bu hastalıkların olușumu ve tedavisi ile ilgili daha çok bilginin edinilmesine neden olacaktır. (Türkderm 201 1; 45: 184-7) Anahtar Kelimeler: Erișkin, obezite, deri bulguları

\section{Summary}

Background: The relationship between systemic diseases and obesity is well-known, but the dermatological effects of obesity are ignored. In the literature, a few articles have appeared concerning the skin findings related to obesity. Our objective was to evaluate the skin findings in obese patients who applied to dermatology outpatient clinic and to compare obese and non-obese outpatients. Material and Method: A total 640 patients (300-in study group, 340-in control group) were included in the study. All subjects were asked questions about socio-demographic features and presence of coexisting systemic diseases. Body mass index was calculated, dermatologic examination was performed, and diagnosis was recorded. Data were evaluated statistically.

Results: Three-hundred obese patients (study group; 229 females, 71 males, mean age: 45.89 years) and 340 non-obese outpatients (control group; 160 females, 180 males, mean age: 38.99 years) were included in our study. There were more females in the study group and the mean age was higher than the control group. Most common skin findings of obese patients were: Skin tag $(53.3 \%)$, plantar hyperkeratosis $(29.6 \%)$, fungal infections $(25.3 \%)$, striae $(20.3 \%)$ and acanthosis nigricans (15.3\%). Fungal infections, intertrigo, varicose veins and keratosis pilaris were more common in females than males in the study group. Within the study group, patients with skin tag, acanthosis nigricans and plantar hyperkeratosis had higher BMI.

Conclusion: Skin tag, plantar hyperkeratosis, fungal infections, striae and acanthosis nigricans were found to be the most common skin diseases in obese patients in our study. Studies related with pathophysiologic features of the skin of obese patients will give more information about the development and treatment of these diseases. (Turkderm 2011; 45: 184-7)

Key Words: Adult, obesity, skin findings

Yazışma Adresi/Address for Correspondence: Dr. Hilal Kaya Erdoğan, Șị̦ii Etfal Eğtitim ve Araștırma Hastanesi, Deri ve Zührevi Hastallklar Kliniği, Istanbul, Türkiye Tel.: +90 2122223426 E-posta: hilalkayaaa@yahoo.com Geliş Tarihi/Received: 02.08.2010 Kabul Tarihi/Accepted: 08.03.201 1

Türkderm-Deri Hastalıkları ve Frengi Arșivi Dergisi, Galenos Yayınevi tarafından basılımıștır. Turkderm-Archives of the Turkish Dermatology and Venerology, published by Galenos Publishing. 


\section{Giriş}

Obezite genel olarak bedenin yağ kütlesinin, yağsız kütleye oranının aşırı artması sonucu boy uzunluğuna göre vücut ağırlığının arzu edilen düzeyin üstüne çıkmasıdır'. Dünya Sağlık Örgütü (DSÖ) tarafından da obezite, sağlığı bozacak ölçüde vücutta aşırı yağ birikmesi olarak tanımlanmıştır². Bazı yazarlar obeziteyi fizyolojik, organik, sistemik, hormonal, metabolik, estetik, psikolojik ve sosyal sorunlara yol açabilen bir hastalık olarak tanımlamaktadır ${ }^{3}$.

Obezite tüm dünyada ve Türkiye'de giderek en önemli sağlık sorunlarından biri haline gelmiştir. Obez bireylerin prevalansı yıllar içinde sedanter yaşam, diyetsel ve sosyoekonomik faktörlerin etkisiyle artmaktadır. DSÖ verilerine göre Dünya'da 2008 yılında 400 milyon obez, 1,4 milyar fazla kilolu varken; bu rakamın 2015 yılında 700 milyon obez, 2,3 milyar fazla kilolu olacağı tahmin edilmektedir (2). Obezitenin en sık görüldüğü Amerika Birleşik Devletleri'nde (ABD) Kronik Hastalıkları Önleme ve Kontrol Merkezi (CDC) tarafından NHANES (ABD-Ulusal Beslenme ve Sağlık Araştırması) çalışmasına göre obezitenin 2005-2006 yılında erkeklerde \%33,3, kadınlarda ise \%35,3 olarak tespit edildiği açıklanmıştır. Avrupa'da yetişkinlerde fazla kilolu olma prevalansı erkeklerde \%32-79, kadınlarda ise \%28-78 arasında değişmektedir. Ülkemizde ise Gültekin ve ark.'nın erişkinlerde obeziteyi araştırdıkları çalışmada obezite prevalansı kadınlarda \%34,19, erkeklerde ise \%20 olarak saptanmıştır.

Obezitenin koroner arter hastalığı, diyabet, hipertansiyon gibi sistemik hastalıklar ile ilişkisi iyi bilinmekte, ancak dermatolojik etkileri göz ardı edilmektedir. Oysa ki obezite derinin bariyer fonsiyonunu, sebum üretimini, ter bezlerini, lenfatikleri, kollajen yapısı ve fonsiyonunu, yara iyileşmesini ve mikrodolaşımı etkilemektedir. Obezitenin pek çok deri bulgusu ve deri hastalığı ile ilişkili olduğu bilinmektedir ${ }^{5.8}$. Ancak bu konu ile ilgili fazla sayıda araştırma bulunmamaktadır. Bu çalışmanın amacı obezlerde görülen deri bulgularını saptamak ve sonuçları obez olmayan hastalar ile karşılaştırmaktı.

\section{Gereç ve Yöntem}

Ekim 2009-Mart 2010 tarihleri arasında hastanemiz Dermatoloji Polikliniği'ne başvuran 300 obez hasta ile obez olmayan 340 hasta çalışmaya alındı. Hastaların sosyodemografik özellikleri, eşlik eden sistemik hastalık varlığı sorgulandı. Boy ve vücut ağırlığı ölçülerek beden kitle indeksleri hesaplandı. Beden kitle indeksi (BKi) vücut ağırlığının boy uzunluğunun karesine bölünmesiyle ölçüldü $\left(\mathrm{kg} / \mathrm{m}^{2}\right)$. Beden kitle indeksi 30 ve üzeri olan hastalar obez olarak kabul edildi. Dermatolojik muayeneleri yapılarak bulgular kaydedildi ve fotoğraflandı. On sekiz yaş altı hastalar ve gebeler çalışma dışı bırakıldı. Elde edilen verilerin analizi SPSS 15,0 paket programında yapıldı. İstatistiksel değerlendirmelerde ki-kare testi kullanıldı. Yaş değişkeni, çalışma ve kontrol

Tablo 1. Hastaların yaş ve cinsiyete göre dağılımı

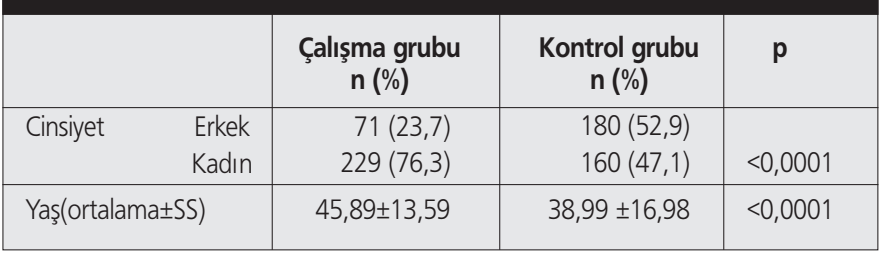

grupları arasında bağımsız gruplarda t testi ile kıyaslandı. ỉki grup arasında cinsiyetlerin farklı olması nedeniyle deri bulgularının karşılaştırması kadın ve erkeklerde ayrı olarak değerlendirildi. Bu karşılaştırmalar Ki-kare testi ve Fisher kesin olasılık testleri ile yapıldı. Ayrıca her bir deri bulgusuna ait BKI'leri karşılaştııııırken bağımsız gruplarda t testi ve Mann Whitney U testi kullanıldı. p<0,05 değeri istatistiksel olarak anlamlı kabul edildi.

\section{Bulgular}

Çalışmamıza; 300 obez (çalışma grubu) ve 340 obez olmayan (kontrol grubu) dermatoloji poliklinik hastası alındı. Çalışma grubunun; 229'u $(\% 76,3)$ kadın, 71'i $(\% 23,7)$ erkekti. Yaşları 18-77 arasında değişiyor-

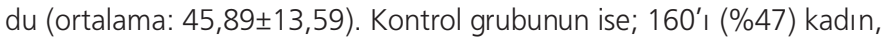
180'i (\%53) erkekti. Yaşları 18-88 arasında değişiyordu (ortalama: $38.99 \pm 16,98)$. Iki grup yaş ve cinsiyet açısından istatistiksel olarak anlamlı derecede farklı bulundu (Tablo 1). Çalışma grubunda kadınlar, kontrol grubuna göre istatistiksel olarak anlamlı derecede daha fazlay$d_{\imath}(p<0,0001)$. Çalışma grubunun yaş ortalaması, kontrol grubundan istatistiksel olarak anlamlı derecede daha yüksekti $(p<0,0001)$.

Eşlik eden sistemik hastalık varlığı sorgulandığında; çalışma grubunun 131 'inde $(\% 43,7)$, kontrol grubunun ise 91 'inde $(\% 26,8)$ hipertansiyon vardı. Her iki grupta da en sık eşlik eden sistemik hastalık hipertansiyondu. Diyabetes mellitus ise çalışma grubunda 54 (\%18) hastada, kontrol grubunda ise $13(\% 3,8)$ hastada mevcuttu.

Çalışma grubundaki hastalarda saptanan en sık 10 hastalık; akrokordon (160), plantar hiperkeratoz (89), mantar infeksiyonları (76), stria (61), akantozis nigrikans (46), ekzemalar (43) bakteriyel infeksiyonlar (38), variköz venler (23), psoriazis (20), ve intertrigo (20) idi (Tablo 2). Çalışma grubunda gözlenen en sık 10 hastalık, kontrol grubu ile karşılaştırılığında; akrokordon, akantozis nigrikans, plantar hiperkeratoz, bakteriyel hastalıklar, stria ve psoriazis hem erkeklerde, hem de kadınlarda iki grup arasında istatistiksel olarak anlamlı olarak fazla saptandı. Ancak, ekzema grubu hastalıklar kontrol grubunda daha fazla gözlendi ve fark istatistiksel olarak anlamlı değildi $(p>0,05)$. Mantar hastalıkları, variköz venler ve intertigo grubu hastalıklar, kadınlarda erkeklere göre istatistiksel olarak anlamlı derecede fazla görüldü (Tablo 2).

Çalışma grubundaki hastalar içinde, spesifik deri bulgusu olan ve olmayanların BKi'leri karşılaştırıldığında akrokordon, akantozis nigrikans ve plantar hiperkeratoz olanların BKi'leri, olmayanlara göre istatistiksel olarak anlamlı derecede daha fazlaydı. Diğer hastalıklar arasında istatistiksel olarak anlamlı bir fark saptanmadı (Tablo 3).

\section{Tartışma}

Literatürde obezlerde görülen deri bulgularını inceleyen az sayıda çalışma bulunmaktadır. Bu çalışmalara göre, obezlerde çok sayıda dermatoz görülmektedir, ve bazı dermatozların sıklığı BKi artışı ile doğru orantılıdır $r^{9,10}$.

Bu çalışmada Türk obezlerde görülen deri hastalıkları araştırılmıştır. Obezlerden oluşan çalışma grubunu kontrol grubu ile kıyasladığımızda, kadın hastalar daha fazla, yaş ortalaması daha yüksek bulunmuştur. Bu sonuç genel populasyonda da obezitenin kadınlarda ve ileri yaşta daha fazla görülmesi verisiyle örtüşmektedir ${ }^{4}$. Literatürdeki çalışmalara benzer şekilde, en sık saptanan sistemik hastalıklar hipertansiyon ve diyabetes 
Tablo 2. En sık görülen deri bulgularında çalışma ve kontrol gruplarının karşılaştırıması

\begin{tabular}{|c|c|c|c|c|c|c|}
\hline & & \multicolumn{2}{|c|}{ Çalışma grubu } & \multicolumn{2}{|c|}{ Kontrol grubu } & \multirow[b]{2}{*}{$p$} \\
\hline & & $\mathrm{n}(\%)$ & $\mathrm{n}(\%)$ & $n(\%)$ & $\mathrm{n}(\%)$ & \\
\hline Akrokordon & $\begin{array}{l}\text { Erkek } \\
\text { Kadın }\end{array}$ & $\begin{array}{r}36(22,5) \\
124(77,5)\end{array}$ & $160(53,3)$ & $\begin{array}{r}6(37,5) \\
10(62,5)\end{array}$ & $16(4,7)$ & $\begin{array}{l}<0,0001 \\
<0,0001\end{array}$ \\
\hline Plantar hiperkeratoz & $\begin{array}{l}\text { Erkek } \\
\text { Kadın }\end{array}$ & $\begin{array}{c}8(8,9) \\
81(91,1)\end{array}$ & $89(29,6)$ & $\begin{array}{l}3(42,8) \\
4(57,2)\end{array}$ & $7(2)$ & $\begin{array}{c}0,002 \\
<0,0001\end{array}$ \\
\hline Derinin mantar hastalıkları * & $\begin{array}{l}\text { Erkek } \\
\text { Kadın }\end{array}$ & $\begin{array}{l}23(30,3) \\
53(69,7)\end{array}$ & $76(25,3)$ & $\begin{array}{l}41(65) \\
22(35)\end{array}$ & $63(18,5)$ & $\begin{array}{l}0,115 \\
0,021\end{array}$ \\
\hline Stria & $\begin{array}{l}\text { Erkek } \\
\text { Kadın }\end{array}$ & $\begin{array}{r}8(13,1) \\
53(86,9) \\
\end{array}$ & $61(20,3)$ & $\begin{array}{l}2(33,3) \\
4(66,7)\end{array}$ & $6(1,7)$ & $\begin{array}{c}0,001 \\
<0,0001\end{array}$ \\
\hline A.nigrikans & $\begin{array}{l}\text { Erkek } \\
\text { Kadın }\end{array}$ & $\begin{array}{l}15(24,6) \\
31(75,4)\end{array}$ & $46(15,3)$ & $\begin{array}{l}0(0) \\
1(100)\end{array}$ & $1(0,3)$ & $\begin{array}{l}<0,0001 \\
<0,0001\end{array}$ \\
\hline Ekzema ** & $\begin{array}{l}\text { Erkek } \\
\text { Kadın }\end{array}$ & $\begin{array}{l}10(23,8) \\
32(76,2)\end{array}$ & $42(14)$ & $\begin{array}{l}40(60,6) \\
26(39,4)\end{array}$ & $66(19,4)$ & $\begin{array}{l}0,146 \\
0,535\end{array}$ \\
\hline Derinin bakteriyel hastalıkları ${ }^{\star \star \star}$ & $\begin{array}{l}\text { Erkek } \\
\text { Kadın }\end{array}$ & $\begin{array}{l}11(28,9) \\
27(71,1)\end{array}$ & $38(12,6)$ & $\begin{array}{l}9(81,8) \\
2(18,2)\end{array}$ & $11(3,2)$ & $\begin{array}{c}0,006 \\
<0,0001\end{array}$ \\
\hline Variköz venler & $\begin{array}{l}\text { Erkek } \\
\text { Kadın }\end{array}$ & $\begin{array}{c}1(4,3) \\
22(95,7)\end{array}$ & $23(7,6)$ & $\begin{array}{l}1(33,3) \\
2(66,7)\end{array}$ & $3(0,9)$ & $\begin{array}{l}0,491 \\
0,001\end{array}$ \\
\hline Psoriazis & $\begin{array}{l}\text { Erkek } \\
\text { Kadın }\end{array}$ & $\begin{array}{c}6(30) \\
14(70)\end{array}$ & $20(6,6)$ & $\begin{array}{l}3(50) \\
3(50)\end{array}$ & $6(1,7)$ & $\begin{array}{l}0,017 \\
0,044\end{array}$ \\
\hline Intertrigo & $\begin{array}{l}\text { Erkek } \\
\text { Kadın }\end{array}$ & $\begin{array}{c}1(5) \\
19(95)\end{array}$ & $20(6,6)$ & $\begin{array}{l}0(0) \\
3(100)\end{array}$ & $3(0,9)$ & $\begin{array}{l}0,283 \\
0,007\end{array}$ \\
\hline
\end{tabular}

Tablo 3. Çalışma grubunda spesifik deri bulgusu olan ve olmayanların BKI'lerinin karşılaştırıması

\begin{tabular}{|l|c|c|c|}
\hline & \multicolumn{2}{|c|}{ BKi } & Bulgu var \\
\hline Akrokordon & $36,89 \pm 5,13$ & $35,00 \pm 5,26$ & 0,002 \\
\hline Plantar hiperkeratoz & $37,51 \pm 5,18$ & $35,37 \pm 5,19$ & 0,001 \\
\hline Stria & $34,89 \pm 4,31$ & $36,29 \pm 5,46$ & 0,064 \\
\hline Akantozis nigrikans & $38,07 \pm 4,89$ & $35,63 \pm 5,26$ & 0,004 \\
\hline Ekzema & $36,01 \pm 6,18$ & $36,01 \pm 5,12$ & 0,99 \\
\hline Variköz venler & $38,31 \pm 7,74$ & $35,82 \pm 4,98$ & 0,154 \\
\hline Psoriazis & $36,27 \pm 5,32$ & $35,99 \pm 5,27$ & 0,816 \\
\hline Intertrigo & $36,01 \pm 4,44$ & $36,01 \pm 5,32$ & 0,983 \\
\hline
\end{tabular}

mellitus idi ve bu hastalıklar obez grupta daha fazla sıklıktaydı․ Bu çalışmada obez hastalarda en sık görülen 5 hastalık sırasıyla; akrokordon $(\% 53,3)$, plantar hiperkeratoz $(\% 29,7)$, mantar infeksiyonları $(\% 25,3)$, stria $(\% 20,3)$ ve akantozis nigrikans $(\% 15,3)$ olarak saptanmıştır.

Yağ dokusu, sadece lipidlerin birikmesini sağlayan bir depo değil, aynı zamanda endokrin, metabolik ve inflamatuvar sinyallerin birbirleriyle bağlantısının olduğu bir organdır. Leptin ve resistin gibi adipokinlerin ve tümör nekroz faktör-alfa (TNF- $\alpha$ ) ve interlökin-6 (IL-6) gibi proinflamatuvar sitokinlerin deri fizyolojisi ve patofizyolojisinde önemli rol oynadıkları düşünülmektedir. Özellikle insülin direnci, inflamasyon ve yara iyileşmesini düzenleyen sitokinler yağ dokuda bulunmaktadır. Bu durum obezite ile bazı dermatozlar arasındaki bağlantıyı açıklamaktadır ${ }^{5,10}$. Akrokordon bazı metabolik hastalıklarda görülen papillomatöz lezyonlardır. Diyabet ve insülin direnci ile kuvvetli bağlantısı olduğu bildirilmek- tedir. Çalışmalarda, akrokordonun ateroskleroz ve kardiovasküler hastalıklar için önemli bir belirteç olabileceği öne sürülmektedir ${ }^{11}$. Çalışmamızda akrokordon, obezlerde saptanan en sık deri bulgusuydu $(\% 53,3)$ ve hastaların BKi'leri karşılaştırıldığında, akrokordon görülen grupta, görülmeyen gruba oranla BKi'nin istatistiksel olarak daha yüksek olduğu bulundu. Bu sonuç, Garcia ve ark.'nın bulguları ile uyumlu olup akrokordonun obeziteyle direkt ilişkisi olduğu şeklinde yorumlanabilir ${ }^{9}$. Plantar hiperkeratoz, obezlerde aşırı kilo nedeniyle yürürken ve ayakta iken plantar bölgedeki basıncın artması sonucu ortaya çıkmaktadır. Illk olarak Garcia ve ark.'nın çalışmasında bildirilmiştir. Çalışmamızda benzer klinik paternde görüldüğü gibi plantar hiperkeratozun nal şeklinde topuklarda yerleştiğini tespit etmişlerdir. Obezitenin şiddeti ile plantar hiperkeratoz varlığı arasında bir korelasyon bulunmuştur 5,9,10.

Derinin mantar hastalıkları, çalışmamızda en sık görülen 3. hastalık grubuydu. Bu hastalıklar, kontrol grubuna kıyasla daha fazlaydı ancak, erkeklerde istatistiksel olarak anlamlı bir fark yoktu. Toplumumuzda erkek hastalarda mantar infeksiyonları en sık görülen deri hastalığı olması nedeniyle bu sonuç elde edilmiş olabilir. Kadınlarda ise oran istatistiksel olarak anlamlı derecede yüksek bulundu. Bu durum, geleneksel giyinme alışkanlıkları ve aşırı terlemenin mantar hastalığı riskini artırdığı şeklinde yorumlanabilir.

Stria ve akantozis nigrikans, çalışmamızda obez grupta sık görülen hastalıklardandı. Her iki hastalığın sıklığı, obezite şiddeti ile doğru orantılı olarak bildirilmiştir ${ }^{9,10}$. Akantozis nigrikans, insülin direnci ve hiperinsülinemi olan hastalarda daha sık saptanmaktadır. Akantozis nigrikans bulunan obez hastalar bu yönden mutlaka araştırılmalıdır ${ }^{6}$. Obezlerde bakteriyel infeksiyon sıklığı arttığı bilinmektedir. Özellikle 
rekürren fronkülozis ve erizipel başta olmak üzere çok çeşitli deri infeksiyonu gözlenmektedir ${ }^{5}$. Obez hastalarımızda bakteriyel infeksiyonlar, kontrol grubuna göre anlamlı derecede fazla saptanmıştır. Çalışmamızda intertrigo ayrı bir hastalık olarak ele alınmıştır ve en sık görülen onuncu hastalık olarak saptanmıştır. Intertrigo friksiyon ve aşırı nemli ortama bağlı olarak oluşmaktadır ${ }^{5}$. Obez hastalarda, özellikle kadınlarda istatistiksel olarak daha yüksek bulunmuştur. Friksiyon, maserasyon, nemli ortam, aşırı terleme ve oklüzyon bakteri ve mantar kolonizasyonunu artırmaktadır ${ }^{8}$.

Çalışmamızda obezite ile yapılan çalışma sonuçlarından farklı olarak psoriazis, en sık 10 hastalık içinde yer almıştır. Çalışmanın dermatoıji polikliniğinde yapıımış olması yüksek oranı açıklayabilir. Psoriazis sıklığı kontrol grubuna göre anlamlı oranda fazlaydı. Psoriazis ile obezite arasındaki ilişki daha önce bildirilmiş ve psoriazisin klinik şiddeti ile BKi arasında doğru orantı olduğu öne sürülmüştür. Primer olarak adipozitlerde üretilen leptin ve adiponektin gibi sitokinlerin psoriazis patogenezinde önemli rol oynadığı gösterilmiştir ${ }^{12-14}$.

Kontrol grubuna kıyasla istatistiksel olarak çalışma grubunda fazla görülen ilk beş hastalık (akrokordon, plantar hiperkeratoz, stria, akantozis nigrikans ve bakteriyel infeksiyonlar) literatürde saptanan bulgularla uyumluydu. Yapılan çalışmalarda ilk üç hastalık için şiddetli obezitenin deri belirteçleri olduğu bildirilmektedir ${ }^{10}$. Obezlerde görülen deri hastalıkları bazen sistemik başka bir hastalığın göstergesi olabileceği gibi bazen de hastaların yaşam kalitesini olumsuz yönde etkilemektedir. Obezlerde deride oluşan patofizyolojik özelliklerin aydınlatılması ile ilgili çalışmalar, bu hastalıkların oluşumu ve tedavisi ile ilgili daha çok bilginin edinilmesine neden olacaktır.

\section{Kaynaklar}

1. Sağlık Bakanlığı. http://wwww.beslenme.saglik.gov.tr/index.html

2. World Health Organisation. http://www.who.int/topics/obesity/en /index.html. May 2010

3. Keskin S, Sayalı E, Temeloğlu E, Ekizoğlu I: Obezite ve inflamasyon. Turkiye Klinikleri J Med Sci 2005;25:636-41.

4. Gültekin T, Ozer BK, Akin G, Bektaş $Y$, Sağir $M$, Güleç E: Prevalence of overweight and obesity in Turkish adults. Anthropol Anz 2009;67:205-12.

5. Yosipovitch G, DeVore A, Dawn A: Obesity and the skin: skin physiology and skin manifestations of obesity. J Am Acad Dermatol 2007;56:901-16.

6. Hahler B: An overview of dermatological conditions commonly associated with the obese patient. Ostomy Wound Manage 2006;52:34-6,38,40.

7. García Hidalgo L: Dermatological complications of obesity. Am J Clin Dermatol 2002;3:497-506.

8. Scheinfeld NS: Obesity and dermatology. Clin Dermatol 2004;22:303-9.

9. García-Hidalgo L, Orozco-Topete R, Gonzalez-Barranco J, Villa AR, Dalman JJ, Ortiz-Pedroza G: Dermatoses in 156 obese adults. Obes Res1999;7:299-302.

10. Guida B, Nino M, Perrino NR, Laccetti R, Trio R, Labella S, Balato N: The impact of obesity on skin disease and epidermal permeability barrier status. J Eur Acad Dermatol Venereol 2010;24:191-5.

11. Sari R, Akman A, Alpsoy E, Balci MK: The metabolic profile in patients with skin tags. Clin Exp Med 2010;10:193-7.

12. Zhang $C$, Zhu $K$, Zheng $H$, Cui $Y$, Zhou $F$, Chen $Y$, et al: The effect of overweight and obesity on psoriasis patients in Chinese Han population: a hospital-based study. J Eur Acad Dermatol Venereol 2010;25:87-91.

13. Johnston A, Arnadottir S, Gudjonsson JE, Aphale A, Sigmarsdottir AA, Gunnarsson SI, et al: Obesity in psoriasis: leptin and resistin as mediators of cutaneous inflammation. Br J Dermatol 2008;159:342-50.

14. Bardazzi F, Balestri R, Baldi E, Antonucci A, De Tommaso S, Patrizi A: Correlation between BMI and PASI in patients affected by moderate to severe psoriasis undergoing biological therapy. Dermatol Ther 2010;23:14-9. 